\title{
Manajemen krisis public relations dalam menangani penolakan imunisasi measles rubella
}

\author{
Wulan Yulianti ${ }^{1}$, Rino Febrianno Boer ${ }^{2}$ \\ ${ }^{1,2}$ The London School of Public Relations, Jakarta, Indonesia
}

\begin{abstract}
ABSTRAK
Pada tahun 2017 fenomena imunisasi Measles rubella menarik perhatian publik. Adanya tindakan penolakan dari para orang tua menghasilkan pemberitaan negatif dan mengantarkan Kementerian Kesehatan pada situasi krisis. Public relations merupakan divisi yang berperan untuk melindungi dan mempertahankan reputasi yang dimiliki oleh organisasi melalui tindakan manajemen krisis. Tujuan penelitian ini yaitu ingin mengetahui manajemen krisis yang dilakukan oleh public relations Kementerian Kesehatan yang diperdalam dengan menggunakan Situational Crisis Communication Theory. Metode penelitian yang digunakan yaitu pendekatan kualitatif dengan menggunakan teknik wawancara mendalam serta mengumpulkan dokumen terkait. Hasil penelitian menunjukkan bahwa manajemen krisis yang dilakukan oleh public relations Kementerian Kesehatan pada tahap pre-krisis adalah kegiatan monitoring media. Saat krisis terjadi respon yang dilakukan tergolong strategi diminish untuk mengurangi dampak negatif dari peristiwa krisis. Beberapa tindakan yang dilakukan yaitu bekerja sama dengan Komite Nasional Pencegahan dan Penanggulangan Kejadian Ikutan Pasca Imunisasi, penyebaran release melalui website, berkomunikasi dengan Pemerintahan daerah, Dinas Kesehatan daerah, serta memanfaatkan media tradisional dan digital. Pada tahap post-krisis dilakukan dialog dengan Majelis Ulama Indonesia untuk melakukan kajian lebih lanjut mengenai kehalalan vaksin. Kesimpulan dalam penelitian ini menunjukkan bahwa penanganan krisis terjadi karena perbaikan komunikasi dan kerja sama dengan para stakeholder. Adapun sarannya adalah sebaiknya ketika terjadi perbedaan pemahaman dengan Majelis Ulama Indonesia, public relations Kementerian Kesehatan dapat melakukan komunikasi yang lebih cepat agar masalah segera teratasi.
\end{abstract}

Kata-kata Kunci: Manajemen krisis; scct; imunisasi; measles; rubella

\section{Public relations crisis management in handling the rejection of measles rubella immunization}

\begin{abstract}
In 2017 the Measles rubella immunization phenomenon caught the public's attention. The act of rejection from parents resulted in negative coverage and led the Ministry of Health to a crisis. Public relations is a division whose role is to protect and maintain the reputation of an organization through crisis management actions. The purpose of this research is to explore crisis management conducted by public relations of the Ministry of Health using Situational Crisis Communication Theory. The research method used is a qualitative approach using in-depth interview techniques and by collecting related documents. The results show that the crisis management carried out by the Ministry of Health public relations at the pre-crisis stage was media monitoring. When a crisis occurs, the response classified as a diminished strategy, reducing the negative impact of a crisis. Some of the actions taken are working with the National Committee of Prevention and Eradication of Post-Immunization Events, disseminating releases through the website, communicating with local governments, regional health offices, and utilizing traditional and digital media. In the post-crisis stage, a dialogue was held with the Indonesian Ulema Council to conduct further studies on the halal vaccine. The conclusion in this study shows that the handling of crises occurs because of improved communication and cooperation with stakeholders. The suggestion is that when there is a difference in understanding with the Indonesian Ulema Council, the Ministry of Health's public relations able to organize faster and effective communication so that the problem can be immediately resolved.
\end{abstract}

Keywords: Crisis management; scct; immunization; measles; rubella

Korespondensi: Wulan Yulianti S.I.Kom. The London School of Public Relations Jakarta. Jl. Jend. Sudirman No. Kav. 32, RT.12/RW.11, Karet Tengsin, Kota Jakarta Pusat, Jakarta 10250.Email: 15110191232@1spr.edu 


\section{PENDAHULUAN}

Pada tahun 2017 Kementerian Kesehatan menyelenggarakan program kampanye imunisasi Measles Rubella (MR) fase pertama, di wilayah pulau Jawa. Program imunisasi yang dibuat untuk tujuan baik, ternyata mendapatkan respons penolakan dari para orang tua. Peristiwa penolakan berlangsung di beberapa wilayah yang berbeda dan menyebabkan pemberitaan negatif bagi Kementerian Kesehatan.

Media memberitakan beberapa masalah, yang menjadi alasan penolakan para orang tua. Masalah pertama yaitu karena dampak negatif setelah imunisasi. Banyaknya kasus-kasus yang menggambarkan dampak negatif dari imunisasi Measles Rubella (MR), membuat para orang tua khawatir untuk memberikan izin anaknya mendapatkan imunisasi.

Saat program imunisasi berlangsung tersebar pemberitaan, jika anak-anak yang mendapatkan imunisasi Measles Rubella (MR) akan menerima dampak negatif seperti sakit bahkan meninggal dunia. Salah satunya kasusnya datang dari daerah Lumajang Jawa Timur. Safira Faradika merupakan siswi kelas 5 SD, yang dikabarkan meninggal usai mendapatkan imunisasi Measles Rubella (MR) (Kurniawan, 2017).

Di tengah perkembangannya yang pesat, media sosial juga memberikan peran dalam penyebaran isu mengenai vaksin Measles Rubella (MR). Hal tersebut dibenarkan oleh Direktur Surveilans dan Karantina Kesehatan Kementerian Kesehatan dr. Jane. Menurutnya pemberitaan hoaks atau berita bohong di media sosial mendorong para orang tua untuk melakukan penolakan akan vaksin Measles Rubella (MR) (Lestari, 2017).

Para orang tua memilih media sosial Facebook, untuk menyebarkan informasi satu

Tabel 1 Pemberitaan media mengenai penolakan imunisasi Measles Rubella (MR)

\begin{tabular}{|c|c|c|c|}
\hline Media & $\begin{array}{c}\text { Judul Artikel } \\
\text { - Tanggal }\end{array}$ & $\begin{array}{l}\text { A } 1 \text { a } \mathrm{s} \text { a } \mathrm{n} \\
\text { penolakan }\end{array}$ & Nilai \\
\hline rappler.com & $\begin{array}{l}\mathrm{D} \\
\text { Yogyakarta } \\
\text { masih ada } \\
\text { wali murid } \\
\text { menolak } \\
(01 / 08 / 17)\end{array}$ & $\begin{array}{lr}\text { K e r a } \mathrm{g} \text { u a } \mathrm{n} \\
\text { dengan } & \text { bahan } \\
\text { vaksin } & \text { yang } \\
\text { tidak } & \text { halal } \\
\text { dan dampak } & \text { buruk setelah } \\
\text { imunisasi }\end{array}$ & $(-)$ \\
\hline $\begin{array}{l}\text { Liputan } 6 \text {. } \\
\text { com }\end{array}$ & $\begin{array}{l}\text { Ini Alasan } \\
\mathrm{R} \text { a t u s a n } \\
\text { Orangtua di } \\
\text { Jawa Tengah } \\
\text { Menolak } \\
(16 / 08 / 17)\end{array}$ & $\begin{array}{l}\text { Vaksin MR } \\
\text { mengandung } \\
\text { zat yang } \\
\text { diharamkan } \\
\text { agama }\end{array}$ & $(-)$ \\
\hline $\begin{array}{l}\text { faktualnews. } \\
\text { com }\end{array}$ & $\begin{array}{l}\text { Warga Tolak } \\
\text { Im unis a i } \\
\text { Cam a k - } \\
\text { R u b e } 11 \text { a, } \\
\text { B e r a li h } \\
\text { V a k s i n } \\
\text { Haram } \\
(25 / 08 / 17)\end{array}$ & $\begin{array}{l}\text { Vaksin } \\
\text { d i k a b a r k a n } \\
\text { haram serta } \\
\text { dampak setelah } \\
\text { imunisas }\end{array}$ & $(-)$ \\
\hline $\begin{array}{l}\text { Kumparan. } \\
\text { com }\end{array}$ & $\begin{array}{l}\text { Tak Ada } \\
\text { Label Halal, } \\
\text { I m un is a s i } \\
\text { Campak dan } \\
\text { Rubella di } \\
\text { S u m e n e p } \\
\text { Ditolak } \\
(20 / 09 / 17)\end{array}$ & $\begin{array}{l}\text { Vaksin yang } \\
\text { tidak memiliki } \\
\text { label halal }\end{array}$ & $(-)$ \\
\hline
\end{tabular}

Sumber: Media online, 2017 
sama lain mengenai vaksin Measles Rubella (MR). Wujud penolakan para orang tua di media sosial, terlihat melalui group facebook yang bernama Gerakan Anti Vaksin dan Imunisasi. Para orang tua yang memutuskan untuk mengambil tindakan penolakan, ikut bergabung dalam group facebook tersebut.

Masalah kehalalan vaksin menjadi alasan selanjutnya para orang tua melakukan penolakan. Sebagian besar masyarakat Indonesia didominasi oleh warga muslim, sehingga kehalalan menjadi syarat penting bagi mereka untuk bisa menerimanya. Keraguan para orang tua akan kehalalan vaksin bersumber dari polemik perbedaan pendapat yang terjadi antara Kementerian Kesehatan dengan Majelis Ulama Indonesia.

Kementerian Kesehatan menjamin jika vaksin rubella aman dan halal, seperti pemberitaan dari CNN Indonesia berikut ini. Ibu Menteri Kesehatan Nila Moeloek menjelaskan Vaksin MR yang diimpor langsung dari India itu halal. Vaksin measles ditumbuhkan pada embrio ayam sedangkan vaksin rubella ditanam pada stem sel yang berasal dari manusia, jadi tidak ada kata haram disini (Olyvia, 2017). Sedangkan, pemberitaan melalui Detiknews pihak MUI membantah adanya sertifikasi untuk vaksin Measles Rubella (MR). Seperti respon yang dikemukakan oleh Ketua Komisi Fatwa MUI Hasanuddin. Menurutnya jika di lapangan tersebar isu-isu dari manapun yang mengungkapkan vaksin MR sudah halal, hal itu merupakan suatu kebohongan. Ia berharap berita ini dapat diketahui oleh masyarakat karena vaksin Measles Rubella (MR) belum ada kehalalannya saat itu, apalagi dengan sertifikat.

Imunisasi Measles Rubella (MR) pada fase pertama juga terancam untuk dihentikan. Pendapat tersebut bersumber dari Anggota Dewan Pakar Ikatan Cendekiawan Muslim Indonesia (ICMI) Pusat. Brigjen Pol (Purn) Anton Tabah Digdoyo meminta vaksinasi Measles Rubella (MR) untuk dihentikan sementara, karena kehalalannya yang belum jelas ("ICMI Minta Vaksinasi Rubela Dihentikan," 2017).

Melalui penjelasan sebelumnya ditemukan beberapa masalah yang menjadikan para orang tua melakukan penolakan. Beberapa masalah diantaranya yaitu dampak negatif setelah imunisasi dan penyebaran hoaks yang terjadi di media sosial. Selain itu perbedaan pendapat antara Kementerian Kesehatan dengan MUI membuat keraguan akan kehalalan vaksin Measles Rubella (MR), membuat program tersebut terancam untuk diberhentikan.

Munculnya tindakan penolakan dengan beragam permasalahan tersebut, membawa Kementerian Kesehatan pada situasi krisis. Definisi krisis adalah kejadian besar yang memberikan hasil negatif dan berpotensi 
mempengaruhi organisasi, perusahaan, atau industri, serta publiknya, produk, layanan, atau nama baik. Berdasarkan definisi tersebut, peristiwa penolakan yang dialami oleh Kementerian Kesehatan dapat digolongkan sebagai krisis. Kampanye imunisasi Measles Rubella (MR) merupakan program besar. Layanan imunisasi Measles Rubella mendapatkan pemberitaan negatif akibat penolakan karena beragam permasalahan yang muncul. Sehingga peristiwa tersebut memberikan sentimen negatif bagi nama baik Kementerian Kesehatan, selaku lembaga penyelenggara program.

Divisi public relations memiliki tugas besar untuk mengelola komunikasi di sebuah organisasi, termasuk penanganan krisis komunikasi. Tindakan yang dilakukan oleh public relations memfokuskan pada persiapan krisis sebagai strategi untuk meminimalkan kerusakan pada reputasi perusahaan. Kegiatan yang dianggap penting saat melakukan komunikasi krisis yaitu persiapan manajemen krisis. Dari penjelasan tersebut, seharusnya sosok public relations Kementerian Kesehatan juga memberikan peran penanganan krisis dan melakukan kegiatan manajemen krisis, pada peristiwa penolakan imunisasi Measles Rubella (MR) di fase pertama (Coombs \& Holladay, 2010)

Adanya indikasi masalah dan latar belakang ini menghasilkan pertanyaan penelitian tentang bagaimana sebenarnya proses manajemen krisis yang dilakukan oleh public relations Kementerian Kesehatan, dalam menangani krisis komunikasi akibat penolakan imunisasi Measles Rubella (MR). Sejalan dengan latar belakang dalam pendahuluan di atas, diharapkan penelitian ini memberikan tujuan dan manfaat. Manfaat teoritis dari hasil penelitian ini diharapkan dapat menjadi referensi dan acuan bagi penelitian sejenis terkait manajemen krisis. Penggunaan teori Situational Crisis Communication Theory, diharapkan untuk memperkaya strategi manajemen krisis yang bisa dilakukan oleh public relations dalam menjaga reputasi yang dimiliki oleh organisasi. Sedangkan manfaat praktisnya adalah hasil penelitian manajemen krisis yang dilakukan oleh public relations Kementerian Kesehatan dapat dijadikan bahan evaluasi dan pembelajaran bagi organisasi.

Krisis sering kali dilihat sebagai peristiwa yang menakutkan, sehingga sebagian besar organisasi memilih untuk menghindarinya. Menurut (Jessica \& Ilfandi, 2018) aktivitas public relations memberikan peran penting dalam penanganan krisis, karena jika tidak ditangani secara cepat dapat membentuk opini publik yang tidak sesuai dengan fakta di lapangan. Kegiatan penanganan krisis yang dilakukan oleh pihak public relations yaitu 
manajemen krisis.

Penelitian lainnya membenarkan peran penting public relations dalam penanganan krisis. Komunikasi krisis merupakan salah satu peran yang dilakukan oleh public relations. Krisis sendiri datang secara mengejutkan dan menghadirkan ancaman bagi organisasi, perusahaan, atau industri, begitu juga terhadap publik mereka, produk, layanan, ataupun nama baik yang sudah dimiliki (Prastya, 2011). Terdapat tiga ancaman yang ditimbulkan ketika krisis yaitu: keselamatan publik, kerugian finansial, atau kehilangan reputasi (Mak \& AO, 2019).

Adanya krisis dapat mengganggu dan memberikan ancaman proses kerja organisasi. (Suryani \& Sagiyanto, 2018) dalam kesimpulan penelitiannya mengemukakan aktivitas mengelola krisis bukanlah hal yang mudah. Ketika krisis terjadi seorang public relations bukan hanya bertugas untuk sekadar tampil di media. Dalam menangani krisis public relations harus memiliki strategi yang komprehensif, tepat, dan cermat. Sama halnya seperti hasil penelitian (Meyerding, 2019) ketika krisis terjadi diperlukan respon secepat mungkin, termasuk menginformasikan kepada publik tentang semua tindakan yang diambil organisasi untuk menangani krisis agar terlihat transparan. Ketika peristiwa krisis terjadi, seharusnya organisasi mengkomunikasikan informasi dan fakta yang diverifikasi.

Di sisi lain krisis juga memberikan manfaat seperti penjelasan menurut (Mejri \& De Wolf, 2013), menurutnya krisis memiliki potensi sebagai kekuatan baru bagi organisasi dan dapat dijadikan sebagai sebuah pembelajaran. Hal tersebut dilakukan untuk mencegah krisis berikutnya dan bersiap untuk menghadapinya. Tindakan pengelolaan krisis yang bisa dilakukan oleh public relations yaitu manajemen krisis. Coombs \& Holladay menjelaskan manajemen krisis sebagai upaya untuk mencegah atau mengurangi hasil negatif dari krisis untuk melindungi organisasi serta para stakeholder, membagi manajemen krisis menjadi tiga bagian yaitu pre-crisis, crisis dan post-crisis, berikut ini penjelasan dari masing-masing tahapan (Coombs \& Holladay, 2010).

Pre-crisis merupakan tahap sebelum terjadi krisis, tindakan yang dilakukan yaitu mengumpulkan seluruh informasi tentang resiko krisis, menentukan respon yang dilakukan saat krisis dan mempersiapkan sosok terpercaya, yang akan memberikan informasi pada publik. Selanjutnya yaitu crisis, pada tahap organisasi

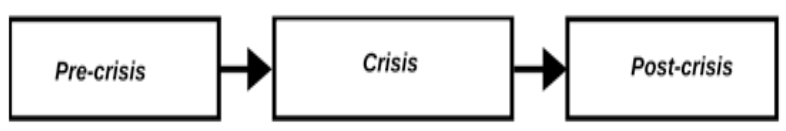

Sumber: Coombs \& Holladay, 2010

Gambar 1 Tahapan Manajemen Krisis 
sedang berada dalam situasi krisis dan harus memberikan respons yang tepat, sehingga bisa tertangani dengan baik. Untuk memperdalam penanganan yang diberikan pada tahapan krisis, akan dianalisis secara mendalam menggunakan Situational Crisis Communication Theory (SCCT).

Situational Crisis Communication Theory (SCCT) dikemukakan pertama kali oleh W. Timothy Coombs sejak tahun 1995. (Coombs
\& Holladay, 2010) menjelaskan penarikan kesimpulan teori ini didasari oleh peristiwa krisis yang memberikan dampak negatif bagi organisasi maupun stakeholder yang bersangkutan, sehingga diperlukan tanggung jawab untuk mengatasinya.

\section{Model Situational Crisis Communication} Theory terdiri dari beberapa elemen. (Coombs \& Holladay, 2010) membagi model SCCT menjadi tujuh elemen, yang terdiri dari crisis

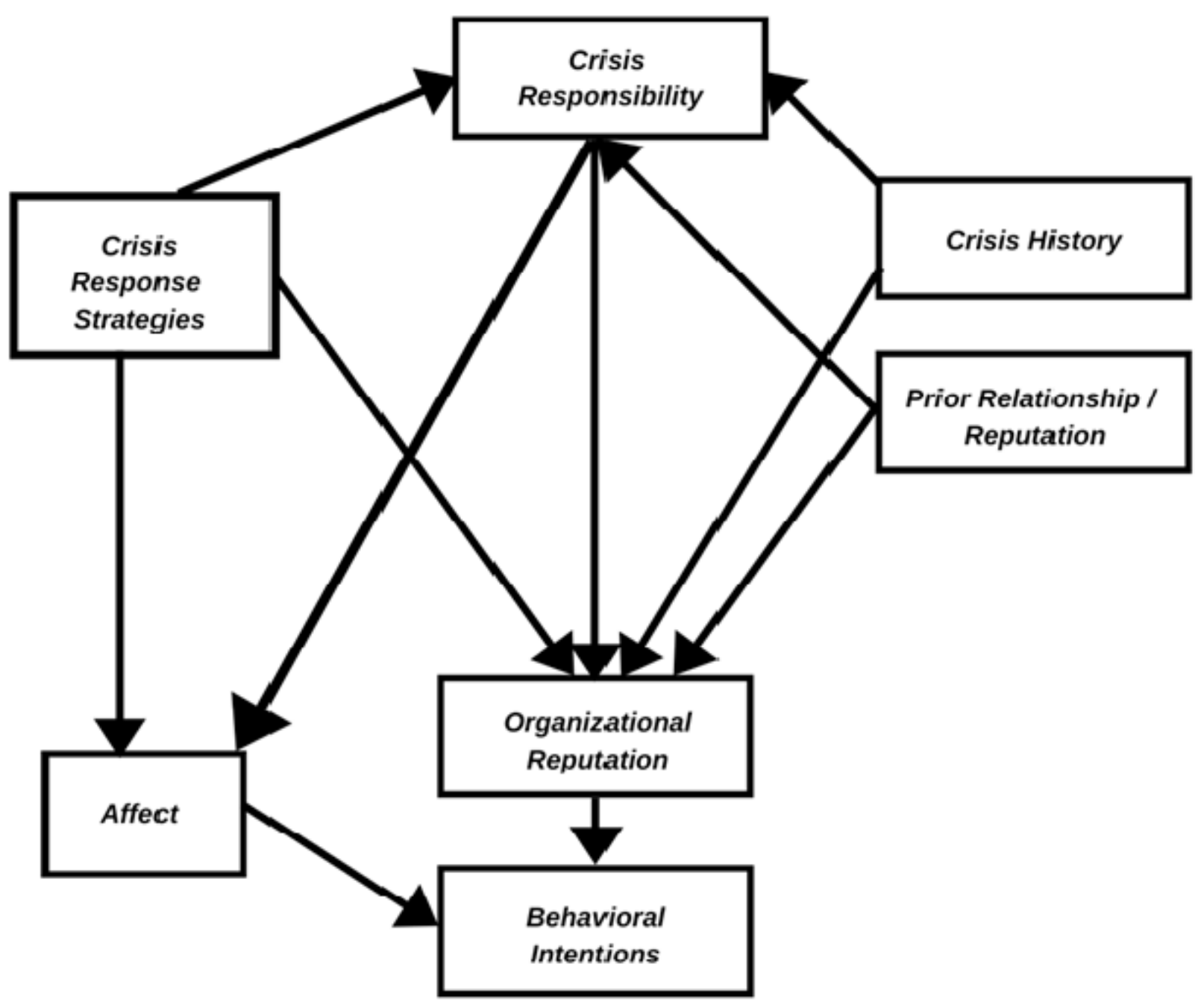

Sumber: Coombs \& Holladay, 2010

Gambar 2 Model Situational Crisis Communication Theory 
responsibility, crisis history, prior reputations, crisis response, affect, organization reputation dan behavioral intention.

Elemen yang pertama yaitu, crisis responsibility yang dijadikan sebagai inti teori untuk mengetahui jenis krisis yang terjadi. Untuk mewakili tingkatan tanggung jawab dan ancaman yang ditimbulkan karena krisis. (Coombs \& Holladay, 2010) membagi jenis crisis responsibility menjadi tiga. Jenis krisis victim memberikan tanggung jawab dan ancaman yang rendah bagi organisasi yang terkena krisis. Kemudian jenis krisis accident memberikan tanggung jawab dan ancaman yang minimal untuk organisasi yang terkena krisis. Terakhir jenis krisis intentional memberikan tanggung jawab dan ancaman yang kuat atau strong bagi organisasi yang mengalami krisis.

Pengalaman krisis yang pernah dialami organisasi di masa lalu menjadi elemen selanjutnyadarisituational crisiscommunication theory. Menurut Coombs \& Holladay, crisis history adalah tindakan untuk melihat ketika suatu organisasi pernah mengalami krisis serupa di masa lalu (Coombs \& Holladay, 2010). Adanya crisis history memberikan sisi negatif dan juga positif bagi organisasi. Sebuah krisis di masa lalu, dapat membentuk pola "perilaku buruk" untuk organisasi. Tetapi crisis history juga dapat memberikan hal positif bagi organisasi, untuk menyusun pesan yang lebih efektif saat krisis terjadi.

Hubungan dengan para stakeholder harus selalu dijaga oleh organisasi, apalagi ketika peristiwa krisis terjadi. Terdapat sebuah pernyataan yang menyebutkan bahwa, dalam melakukan penyelesaian krisis, dibutuhkan analisis stakeholder yang terlibat dalam krisis tersebut (Akhyar \& Pratiwi, 2019). Dalam elements situational communication crisis theory disebut dengan prior reputation yang menjelaskan elemen prior reputation, digunakan untuk melihat seberapa baik atau buruk suatu organisasi memperlakukan para stakeholder-nya (Coombs \& Holladay, 2010). Hal tersebut dilakukan untuk menemukan keadaan umum hubungan antara organisasi dengan para stakeholder.

Organisasi harus merancang strategi, agar bisa merespon krisis dengan tepat. Dari hasil penelitian organisasi maupun perusahaan yang menghadapi krisis yang sama, tetap memiliki respon yang berbeda dalam menangani sebuah krisis (Ham, Hong, \& Cameron, 2012). Dalam

Situational Crisis Communication Theory SCCT membagi Crisis Response Strategy menjadi empat strategi yaitu deny, diminish, rebuild dan reinforce (Coombs \& Holladay, 2010).

Setiap strategi memiliki penjelasannya masing-masing. Strategi yang diberikan cenderung kecil untuk meminimalkan tanggung 
jawab krisis organisasi dan mengurangi keseriusan krisis yang dirasakan. Diminish berusaha untuk mengurangi krisis, tetapi meningkatkan persepsi organisasi dengan menjelaskan alasan dan pembenaran atas apa yang terjadi. Memperkuat strategi mencoba untuk menambahkan informasi positif tentang organisasi. Rebuild merupakan tindakan akomodatif yang dilakukan oleh organisasi sebagai upaya untuk meningkatkan persepsi yang dimiliki. Tindakan yang bisa dilakukan oleh organisasi yaitu melakukan permintaan maaf dan memberikan kompensasi kepada korban serta mengambil tanggung jawab penuh atas permasalahan yang terjadi. Reinforce adalah strategi penguatan dengan mencoba menambahkan informasi positif tentang organisasi terutama dari pihak lain. Salah satunya adalah dengan mengingatkan orangorang akan pekerjaan baik yang sudah lakukan di masa lalu.

Media menjadi hal penting bisa dimanfaatkan ketika organisasi mengalami krisis. Menurut juru bicara atau spokesperson, yang dipercaya oleh organisasi harus bertemu dengan media pada tahap awal krisis untuk menyebarluaskan informasi dan berpartisipasi dalam membingkai krisis. Pertanyaan media harus dijawab dengan cepat, akurat, terbuka dan konsisten (Coombs \& Holladay, 2010).

Coombs \& Holladay, menjelaskan, jika sekarang ini dalam menangani krisis komunikasi organisasi dapat menggunakan new media (Coombs \& Holladay, 2010). Contohnya seperti website perusahaan ataupun dari pemberitaan media online. Kemudian social network dan media sosial seperti web blogs, twitter, podcast, youtube dan email. Hasil penelitian dari (Apuke \& Tunca, 2018) praktisi public relations disarankan untuk mengikuti kegiatan media sosial dan menindaklanjutinya. Jika sosial media digunakan dengan sesuai saat krisis, maka dapat digunakan sebagai platform negosiasi yang mengajak interaktivitas dengan publik.

Menurut Coombs \& Holladay, setelah organisasi melakukan crisis response kemudian akan dilihat bagaimana affect atau pengaruh kepada reputation organizational dan juga behavioral intentions dari publik (Coombs \& Holladay, 2010). Tahap terakhir dalam manajemen krisis yaitu post-crisis. Coombs \& Holladay menjelaskan post-crisis sebagai pembelajaran yang diterima organisasi setelah terjadi krisis. Pada tahap ini tetap dibutuhkan komunikasi, untuk mengubah dan menyediakan pesan yang dibutuhkan setelah krisis berlangsung (Coombs \& Holladay, 2010).

Bersumber dari penjelasan permasalahan, latar belakang dan pemaparan literatur review sebelumnya. Penelitian ini berfokus untuk menganalisis manajemen krisis yang dilakukan 
oleh public relations Kementerian Kesehatan dalam menangani penolakan imunisasi Measles Rubella (MR) di tahun 2017 yang diperdalam menggunakan Situational Communication Crisis Theory.

\section{METODE PENELITIAN}

Penelitian ini menggunakan pendekatan kualitatif, karena ingin menggambarkan salah satu peristiwa yang ada dalam kehidupan sosial. Menurut West \& Turner, pendekatan kualitatif untuk menggambarkan detail tentang orang, tindakan, dan peristiwa dalam kehidupan sosial (West \& Turner, 2010). Kemudian, untuk jenis metode yang dipakai yaitu deskriptif.

Teknik pengumpulan data yang digunakan yaitu wawancara mendalam dan collecting data dokumen yang bisa diakses secara offline maupun online. (Yin, 2014) membagi beberapa teknik pengumpulan data untuk pendekatan kualitatif. Dua diantaranya yaitu interview dan collecting data atau dokumen. Menurut (West \& Turner, 2010) wawancara merupakan situasi sosial untuk informan untuk menafsirkan makna pertanyaan. Diperlukan pemahaman yang mendalam mengenai maksud peneliti dalam setiap pertanyaan agar tercapainya pemahaman bersama.

Subjek dalam penelitian ini yaitu pihak public relations Kementerian Kesehatan, perwakilan Majelis Ulama Indonesia dan informan ahli. Divisi yang memiliki peran dan tugas public relations di Kementerian Kesehatan disebut dengan Biro Komunikasi dan Pelayanan Masyarakat. Dalam divisi Biro Komunikasi dan Pelayanan Masyarakat masih dibagi menjadi beberapa sub divisi.

Penelitian ini telah melakukan spesifikasi dengan memilih informan yang menangani manajemen krisis akibat penolakan imunisasi Measles Rubella (MR) di tahun 2017. Pertama yaitu Anjari, S. Kom, SH, MARS (Kepala Bagian Opini Publik Produksi Komunikasi dan Peliputan di Biro Komunikasi dan Pelayanan Masyarakat Kementerian Kesehatan). Kemudian Giri Inayah, SKM, MKM sebagai (Kepala Sub bagian Hubungan Media Massa dan Media Sosial di Biro Komunikasi dan Pelayanan Masyarakat Kementerian Kesehatan). Sebagai upaya memperdalam informasi mengenai program imunisasi Measles Rubella (MR), pihak ketiga yang dijadikan informan yaitu dr. Gertrudis Tandy menjabat sebagai (Kepala Seksi Imunisasi Khusus dan Lanjutan Subdit Imunisasi Kementerian Kesehatan). Divisi tersebut merupakan pembuat program dan masuk ke dalam bagian Direktorat Jenderal Pencegahan dan Pengendalian Penyakit di Kementerian Kesehatan.

Penelitian ini juga mewawancarai salah satu stakeholder Kementerian Kesehatan dalam masalah imunisasi Measles Rubella (MR) yaitu, 
KH. Arwani Faishol merupakan Wakil Sekretaris Komisi Fatwa Majelis Ulama Indonesia (MUI). Kemudian dilakukan juga wawancara bersama informan ahli sebagai sosok yang memiliki pengetahuan mengenai manajemen krisis. Benny Siga Butarbutar, M. Si. sebagai Advisor Media and Communications BOD Perum BULOG dan pernah menjabat sebagai Vice President Corporate Communications Garuda Indonesia. Lokasi penelitian untuk memperoleh data dilakasnakan di wilayah Jakarta.

Teknik analisis data yang digunakan yaitu model Miles dan Huberman yang terdiri dari pengumpulan data, reduksi data, dan conclusion drawing and verification (Sugianto, Don, \& Doho, 2019) Kemudian untuk menguji kredibilitas data dilakukan pengecekan dengan triangulasi. Triangulasi merupakan gagasan untuk melihat sesuatu dari berbagai sudut pandang, untuk meningkatkan akurasi data (West \& Turner, 2010).

\section{HASIL DAN PEMBAHASAN}

Manajemen krisis terbagi menjadi tiga tahapan dimulai dari pre krisis, krisis dan post krisis. Tahap pre krisis merupakan fase sebelum krisis terjadi dilakukan seluruh informasi tentang resiko krisis, tindakan apa yang dilakukan ketika krisis dan mempersiapkan orang ataupun spokesperson (Coombs \&
Holladay, 2010). Hasil penelitian yang didapatkan dari wawancara bersama ketua sub divisi public relations Kementerian Kesehatan. Anjari Kepala Bagian Opini Publik Produksi Komunikasi dan Peliputan menjelaskan jika Kementerian Kesehatan telah menentukan spokesperson yang akan menghadapi media atau publik, serta tindakan monitoring berita.

Pada peristiwa imunisasi Measles Rubella (MR) spokesperson atau juru bicara teknis dibagi menjadi tiga, yang utama yaitu Ibu Menteri Kesehatan, kepala biro komunikasi, dan direktur pembuat program imunisasi. Sebelum terjadi krisis sudah dilakukan monitoring media setiap hari mengenai pemberitaan apa saja yang dimiliki oleh Kementerian Kesehatan sehingga dapat mendeteksi atau melakukan tindakan pencegahan. Begitu pun jawaban dari Inayah sebagai Kepala Sub bagian Hubungan Media Massa dan Media Sosial yang masuk ke dalam sub divisi public relations Kementerian Kesehatan.

"Kita sudah ada aturan hukumnya di Permenkes tentang pejabat yang memberikan keterangan pada pers dan pada publik. Jadi pejabat-pejabat itu yang akan memberikan keterangan. Nah posisi biro komunikasi merupakan posisi yang strategis, jadi memang kepala biro komunikasi tentu menjadi spokeperson". Inayah, 28 Desember 2019, komunikasi pribadi).

Saat penolakan imunisasi Measles Rubella (MR) salah satu spokesperson yang 
memberikan pernyataan yaitu Ibu Menteri Kesehatan Nila Moeloek. Ia menjelaskan jika vaksin Measles Rubella halal, sedangkan menurut MUI pihaknya belum memberikan sertifikasi halal untuk vaksin tersebut. Melalui hasil penelitian kandungan Measles Rubella (MR) yang diselesaikan pada tahun 2018. Faishol sebagai wakil Sekretaris Komisi Fatwa MUI menjelaskan jika vaksin Measles Rubella (MR) hukumnya haram, tetapi karena keadaan genting dan belum ada penggantinya vaksin tersebut menjadi mubah. Saat isu menyebar spokesperson memiliki peran penting untuk menghadapi media dan memberikan informasi kepada publik. Pihak public relations sebaiknya memastikan spokesperson yang akan berbicara kepada publik memahami permasalahan dan didasari dengan fakta yang sudah terverifikasi.

Selaras dengan penjelasan pada pendahuluan, public relations Kementerian Kesehatan mengalami krisis akibat adanya penolakan dari para orang tua mengenai imunisasi Measles Rubella (MR). Pada tahap krisis ini, akan diperdalam menggunakan Situational Crisis Communication Theory. Menurut (Coombs \& Holladay, 2010) penarikan kesimpulan teori ini, didasari karena krisis merupakan peristiwa negatif bagi organisasi sehingga diperlukan tanggung jawab untuk mengatasinya. Penjelasan tersebut, menjadi alasan menggunakan teori ini. Dengan menggunakan situational communication theory, pada tahap krisis ini akan menganalisis secara mendalam bagaimana proses tanggung jawab yang dilakukan oleh public relations Kementerian Kesehatan sebagai upaya penanganan krisis.

Butarbutar sebagai informan ahli yang menjabat Advisor Media and Communications BOD Perum BULOG menjelaskan pentingnya penggunaan SCCT Situational Crisis Communication Theory. Menurutnya terdapat dua hal yang ingin dicapai dalam teori SCCT yaitu kemampuan kita memprediksi reaksi kemarahan publik dan bagaimana kemampuan manajemen public relations dalam menyiapkan strategi respon terhadap krisis.

Situational Crisis Communication Theory (Coombs \& Holladay, 2010) terdiri dari beberapa elements yaitu crisis responsibility, crisis history, prior reputations, crisis response strategies, affect, organization reputation dan behavioral intentions. Elemen pertama yaitu crisis responsibility, yang menjelaskan jenis krisis untuk melihat tanggung jawab serta ancaman yang diterima oleh organisasi ketika terjadi krisis. (Coombs \& Holladay, 2010) membagi jenis krisis menjadi tiga jenis. Dari wawancara bersama Inayah, ditemukan jika peristiwa penolakan imunisasi Measles Rubella (MR) masuk kedalam jenis krisis intentional yang membuat organisasi memberikan tanggung 
jawab strong atau kuat. Kementerian Kesehatan menganggap serius ancaman ini, alasannya jika penolakan dibiarkan dan anak-anak tidak terimunisasi maka dampak yang ditimbulkan akan luar biasa. Selain itu, karena permasalahan ini terjadi secara nasional maka yang melihat pihak internasional sehingga dunia global akan melihat dan menilai program yang dilakukan oleh Kementerian Kesehatan.

Pendapat tersebut, sama halnya dengan pihak narasumber ahli Butarbutar.

“...Krisis yang dialami oleh Kementerian Kesehatan bisa jadi strong karena sepertinya sebuah persoalan atau krisis terlihat kecil, tapi sebenarnya itu bisa berubah secara besar atau lompat menjadi besar karena eskalasinya sudah semakin tidakjelas karena sosial media itu. Dalam krisis kita melihat persoalan itu kecil, sedang atau rendah lagi tapi sudah melihat kepada kemampuan menghitung eskalasi, dan kemampuan merespon dengan cepat. Tindakan sekecil apapun dengan mudah berubah menjadi besar dan pada saat itu ditangani terlambat the damage has already done..." (Butarbutar, 13 Mei 2019, komunikasi pribadi).

Hasil analisis menunjukan bahwa penolakan imunisasi Measles Rubella (MR) di tahun 2017 masuk ke dalam jenis strong atau kuat, karena menyangkut program nasional untuk anak-anak Indonesia. Jika kampanye negatif berhasil, maka penolakan akan semakin meluas dan bisa berdampak pada kesehatan pada anakanak Indonesia itu sendiri. Public relations Kementerian Selain itu adanya penggunaan media sosial dapat mengubah permasalahan dari kecil, hingga melompat menjadi besar dengan cepat. Maka dari itu, saat krisis terjadi dibutuhkan kemampuan perhitungan eskalasi dan juga tindakan respon secara cepat dan tepat.

Coombs \& Holladay, menjelaskan crisis history merupakan proses untuk menganalisis jika organisasi pernah mengalami krisis serupa atau tidak di masa lalu. Menurut Inayah, Kementerian Kesehatan pernah mengalami krisis serupa dan biasanya terjadi terkait program-program imunisasi (Coombs \& Holladay, 2010). Menurutnya kelompok kontra pasti ada, khususnya ketika akan menerapkan vaksin baru. Contoh kasusnya seperti vaksinasi untuk kanker serviks, banyak masyarakat yang menganggap vaksin tersebut dapat membuat anak-anak menjadi mandul. Padahal setelah dilakukan riset, tidak ada indikasi yang menjelaskan bahwa menyebabkan seseorang mandul atau tidak hamil.

Pendapat yang senada juga dijelaskan oleh Tandy sebagai Kepala Seksi Imunisasi Khusus dan Lanjutan Subdit Imunisasi Kementerian Kesehatan. Menurutnya penolakan terjadi pada kelompok-kelompok masyarakat anti vaksin dan memiliki keyakinan untuk menolak. Salah satu alasan mengapa kelompok tersebut melakukan penolakan didasari karena mereka lebih percaya herbal.

Hasil analisis pada elements crisis history menjelaskan, jika Kementerian Kesehatan 
pernah mengalami hal serupa dimasa lalu. Krisis penolakan mengenai program imunisasi pernah terjadi sebelumnya dan biasanya permasalahan seperti ini terjadi pada programprogram baru. Salah satu alasan penolakan terjadi, karena masyarakat mempermasalahkan kandungan dan dampak negatif setelah melaksanakan vaksinasi. Dari crisis history juga ditemukan jika untuk kasus-kasus yang diduga akibat imunisasi ditangani oleh tim ahli independen Komnas KIPI (Kejadian Ikutan Pasca Imunisasi). Dimana tindakan tersebut juga terapkan, untuk kasus penolakan imunisasi Measles Rubella (MR) tahun 2017.

Elemen prior relations menurut (Coombs \& Holladay, 2010) merupakan proses bagaimana hubungan dan perlakuan organisasi stakeholder. Dalam program kampanye imunisasi Measles Rubella (MR) bekerjasama dengan banyak stakeholder. Berikut ini penjelasan Anjari mengenai pihak stakeholder yang bekerjasama dalam program imunisasi Measles Rubella (MR).

"Imunisasi Measles Rubella (MR) bukan program biasa melainkan program panjang dan program lama. Ini bukan hanya cita-cita Indonesia melainkan keinginan dunia. Memang Kementerian Kesehatan menjadi focal point atau pemangku utama namun dibantu oleh stakeholder lain baik dari dalam negeri maupun luar. Seperti Kementerian Pendidikan. Kemudian kepala daerah seperti Gubernur, Bupati, Walikota diajak untuk mendukung program dan menggerakan rakyatnya untuk mengikuti program". (Anjari, 31 Desember 2019, komunikasi pribadi).
Kementerian Kesehatan menjadi focal point atau pemangku utama yang dibantu oleh para stakeholder baik dari dalam maupun luar negeri. Kementerian Kesehatan menyebarkan rilis dan menjelaskan siapa saja stakeholder dalam program imunisasi Measles Rubella (MR). Diantaranya seperti Kementerian Pendidikan, kepala daerah seperti Gubernur, Bupati, Walikota yang diajak untuk mendukung program dan dapat ikut menggerakkan warganya untuk mengikuti program. Setiap stakeholder memiliki peran yang berbeda, seperti Pemerintah Daerah diharapkan dapat membentuk kelompok kerja eliminasi campak dan pengendalian rubella yang sesuai dengan kondisi daerah masing-masing. Selain itu Pemerintah Daerah, Kabupaten / Kota diwajibkan untuk mendukung melalui dana dan tenaga serta persiapan fasilitas yang ada.

Kementerian Pendidikan dan Kebudayaan dan Kementerian Agama memiliki peran untuk menyediakan dan memvalidasi data-data sasaran utama imunisasi massal, membantu membuat surat edaran dan sosialisasi agar imunisasi berjalan sukses. Lembaga-lembaga internasional seperti Badan Kesehatan Dunia (WHO), Badan Dunia untuk Anak-Anak (UNICEF) dan badan-badan Perserikatan Bangsa-Bangsa ikut berpartisipasi melalui pengerahan sumber daya yang ada. Kemudian 
Lembaga-lembaga LSM lokal dan internasional diharapkan membantu melalui sumber daya SDM yang ada dan berkoordinasi dengan Dinas Kesehatan Provinsi/Kabupaten dan Puskesmas setempat (WHO, 2017).

Peran opinion leader di masing-masing daerah diharapkan seperti Tim Penggerak PKK di tiap tingkatan, tokoh masyarakat dan alim ulama untuk menggerakkan kelompok sasaran imunisasi. Organisasi profesi (IDAI, IDI, IBI, PPNI, PERSI) mendukung imunisasi dengan membuat agar surat edaran untuk masing-masing anggotanya. Kementerian Kesehatan dalam upaya menyadarkan masyarakat menggunakan media massa (cetak dan elektronik (radio, TV) dalam menerbitkan berbagai berita, wawancara, dialog, pesan layanan masyarakat, pengumuman publik, dan diskusi (WHO, 2017).

Melalui penjelasan sebelumnya, terlihat banyaknya stakeholder yang diajak oleh Kementerian Kesehatan saat program imunisasi Measles Rubella (MR). Akan tetapi, terdapat salah satu lembaga yang tidak ada yaitu Majelis Ulama Indonesia. Dari hasil analisis menunjukkan, terdapat perbedaan acuan fatwa dari pihak Kementerian Kesehatan, sehingga perbedaan respon dengan Majelis Ulama Indonesia terjadi.

Crisis Response Strategy memiliki tujuan untuk menentukan tanggapan yang diberikan oleh organisasi saat terjadi sebuah krisis
(Coombs \& Holladay, 2010). Hasil analisis menunjukkan jika public relations Kementerian Kesehatan memilih tindakan diminish, yaitu tindakan yang dilakukan untuk mengurangi dampak negatif dari peristiwa krisis. Sama halnya dengan hasil penelitian (Putri, 2019) yang mengartikan strategi diminish sebagai tindakan justifikasi, melalui argumen dan membenarkan tindakannya.

Hasil analisis menunjukkan sebagai upaya penanganan penolakan yang dilakukan oleh para orang tua, public relations Kementerian Kesehatan melakukan beberapa tindakan sesuai dengan permasalahan yang terjadi. Beberapa tindakan yang dilakukan yaitu bekerja sama dengan Komnas KIPI (Kejadian Ikutan Pasca Imunisasi), penyebaran rilis melalui website, berkomunikasi dengan Pemerintahan daerah, Dinas Kesehatan daerah, serta memanfaatkan media tradisional dan digital. Penelitian dari (Kriyantono, 2012) memperkuat situational communication crisis theory, ketika krisis terjadi perusahaan harus berurusan dengan dampak krisis pada para korban. Menurut Inayah untuk mengatasi Kejadian Ikutan Pasca Imunisasi yang disingkat menjadi KIPI. Ketika ada orang yang mengadu bahwa dia kena kasus imunisasi ini kita harus cek dulu benar tidaknya kasus itu karena imunisasi atau tidak. Dari hasil analisis ditemukan jika Public relations Kementerian Kesehatan memanfaatkan crisis history yang 
pernah terjadi sebelumnya. Dalam masalah kejadian negatif pasca imunisasi Measles Rubella (MR) tahun 2017 yang berdampak pada korban anak-anak, penanganannya tetap dilakukan oleh Komisi Komite Nasional Pengkajian dan Penanggulangan Kejadian Ikutan Pasca Imunisasi (Komnas PP KIPI).

Hasil analisis menunjukkan jika masalah perbedaan pendapat di media mengenai kehalalan vaksin antara Majelis Ulama Indonesia dan Kementerian Kesehatan terjadi, karena adanya perbedaan pemahaman. Seperti yang telah dikemukakan oleh Faishol selaku Wakil Sekretaris Komisi Fatwa MUI. "...Vaksin rubella itu dulu kan sudah dilaksanakan sosialisasinya oleh Kemenkes di berbagai wilayah. Tapi tiba-tiba rame, rame itu bisa dicek lagi menyatakan bahwa sudah ada fatwa dari MUI. Kemudian MUI pun menyangga belum ada fatwa tentang vaksin rubella itu tahun 2017 masuk tahun 2018 awalkan gitu. Sehingga rame di media ketika di Kemenkes memberikan penjelasan ada fatwa dari MUI tapi MUI bilang belum ada fatwa tentang vaksin rubella. Dimana Kok bisa terjadi misinformasi, kan terkait dengan informasi ke publik..." (Faishol, 21 April 2019, komunikasi pribadi).

Selain itu Faishol sebagai wakil Sekretaris Komisi Fatwa MUImenambahkan, Kementerian Kesehatan mempunyai pemahaman jika fatwa halal tentang vaksinasi dapat digunakan untuk vaksin apa saja termasuk vaksin rubella. Sehingga pihak Kementerian Kesehatan meyakini jika vaksin imunisasi Measles Rubella (MR) sudah mendapatkan sertifikasi.
Menurut Tandy program Measles Rubella (MR) mengacu pada fatwa MUI No. 4 tahun 2016 yang berisi tentang imunisasi. Saat itu Kementerian berpendapat jika imunisasi Measles Rubella (MR) sudah memiliki fatwa halal sedangkan dari pihak MUI menyangkal pendapat tersebut. Untuk menangani perbedaan pemahaman Kementerian Kesehatan berupaya untuk melakukan rapat dan membuka saluran komunikasi dengan MUI. Berikut ini penjelasan yang dikemukakan oleh Faishol mengenai peristiwa tersebut. Akhirnya pihak Kementerian Kesehatan mendatangi MUI dan dijelaskan pemahaman mengenai fatwa Measles Rubella (MR). Untuk pelaksanaan imunisasi Measles Rubella (MR) harus dibuat fatwa khusus tidak bisa menggunakan fatwa No. 4 tahun 2016. Oleh karena itu dibutuhkan penelitian mengenai kandungan dan unsur-unsur yang ada dalam imunisasi Measles Rubella (MR), sehingga bisa ditentukan kehalalannya.

Program imunisasi Measles Rubella (MR) yang dibuat oleh Kementerian Kesehatan yang mengacu pada fatwa MUI yang sudah ada dan menganggap jika fatwa tersebut bisa diterapkan untuk imunisasi Measles Rubella (MR). Dari hasil analisis dapat dikatakan jika hal tersebut sumber merupakan sumber permasalahan. Kandungan dari imunisasi Measles Rubella (MR) yang baru dibutuhkan penelitian lebih lanjut mengenai kehalalan vaksin. Dari 
pertemuan dan penelitian mengenai vaksin Measles Rubella (MR), dihasilkan fatwa MUI nomor 33 tahun 2018 (MUI, 2018). Dalam fatwa MUI nomor 33 tahun 2018 menjelaskan jika pemanfaatan unsur babi hukumnya haram. Namun, pada saat ini diperbolehkan karena kondisi darurat adanya bahaya yang ditimbulkan akibat tidak diimunisasi dan belum ditemukan vaksin yang halal dan suci. Dalam hal ini, proses pemberian fatwa imunisasi Measles Rubella (MR), terbilang lambat karena baru selesai pada tahun 2018 .

Sebagai upaya melakukan pendekatan kepada pihak yang melakukan penolakan. Kementerian Kesehatan melakukan kerja sama dengan Dinas Kesehatan atau pemerintah daerahnya berbicara dan menjelaskan kepada para orang tua yang melakukan penolakan. Penjelasan dilakukan secara detail, agar mereka dapat menerima imunisasi Measles Rubella (MR).

Pemberitaan negatif yang dimuat oleh media diatasi dengan cara berbeda. Inayah menjelaskan saat penolakan terjadi, public relations Kementerian Kesehatan telah melakukan kegiatan media visit di daerahdaerah atau media-media yang kontroversial. Adanya tindakan tersebut dijadikan sebagai penanganan untuk mereka yang memberikan informasi keliru dan negatif mengenai imunisasi Measles Rubella (MR).
Pemberian informasi yang jelas kepada media juga dilakukan, sehingga dilakukan tindakan cross check. Dimana media menanyakan informasi yang benar dan dari sumber terpercaya yang diwakili oleh pihak public relations Kementerian Kesehatan. Hasil analisis menunjukkan pada saat krisis terjadi, ketika media ditangani dan direspons dengan baik maka mereka melakukan perubahan. Public relations Kementerian Kesehatan lebih menghimbau media untuk menulis ajakan kepada publik karena situasi anakanak Indonesia saat ini yang sedang kritis dan membutuhkan imunisasi Measles Rubella (MR). Seperti yang dijelaskan bahwa media bergerak dari sikap agresif awalnya yang merusak organisasi menjadi saluran komunikasi yang membantu perusahaan berbicara kepada publik.

Seluruh media Kementerian Kesehatan digunakan, baik tradisional media seperti menyebarkan advertorial salah satunya di televisi untuk mengajak dapat berubah dan bisa menerima imunisasi Measles Rubella (MR). Anjari menambahkan jika dalam penanganan penolakan imunisasi Measles Rubella (MR) di fase pertama, menurutnya media yang digunakan "all media jadi misalkan media website kita, majalah media kom, pay media yah kita pasang PSA di tv, kita pasang advertorial di media itu pay media yah kan. Tetapi kadang- 
kadang ada di kanal-kanal resmi kita seperti twitter Instagram semua media" (Anjari, 2019

31 Desember, komunikasi pribadi).

Kementerian Kesehatan juga menggunakan new media seperti penggunaan sosial media Instagram, Youtube, Instagram, Facebook. Sebagai upaya ajakan untuk publik, Kementerian Kesehatan membuat konten video. Di mana sosok yang dimuat dalam video yaitu para orang tua wali yang menggambarkan kesedihannya ketika anaknya yang sudah terkena penyakit rubella. Menurut Inayah sebagai Kepala Sub bagian Hubungan Media Massa dan Media Sosial, hal ini dilakukan sebagai strategi untuk menarik publik. Karena pada dasarnya publik akan lebih percaya kepada orang yang sudah mengalaminya sendiri. Selain dalam bentuk video dibuat juga gambar ajakan singkat dan mudah dibagikan yang isinya yaitu informasi mengenai program serta informasi mengenai program imunisasi Measles Rubella (MR).

Gambar 3 merupakan salah satu konten media sosial yang diunggah dalam Facebook Kementerian Kesehatan. Sosok yang dipilih

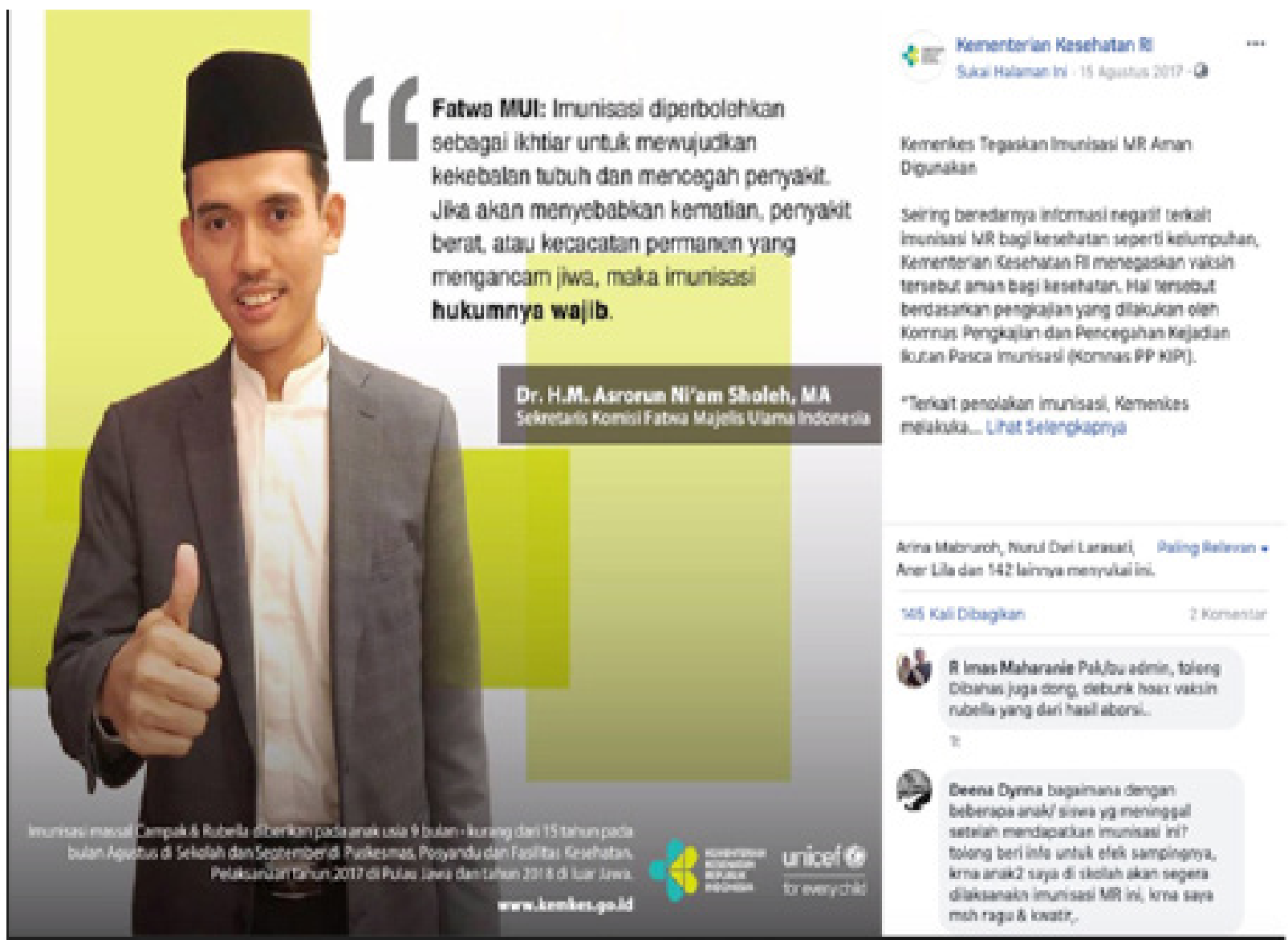

Sumber: Facebook Kemenkes RI, 2017

Gambar 3 Tanggapan Sekretaris Komisi Fatwa Majelis Ulama Indonesia 
yaitu perwakilan dari Majelis Ulama Indonesia yang memberikan tanggapan mengenai imunisasi. Dengan adanya tanggapan dari pihak MUI diharapkan bisa meredakan kehawatiran publik akan hukum Islam vaksin Measles Rubella (MR). Dari hasil analisis saat konten sosial media disebarkan memang terlihat kurang responsif, karena tidak dilangsungkannya komunikasi dua arah dengan publik. Contohnya seperti masih ada komentar yang diabaikan dan tidak diberikan respons. Lalu untuk penanganan kehalalan vaksin memang berlangsung lama dan memakan waktu, karena fatwanya baru terselesaikan satu tahun kemudian.

Pada tahapan affect di dalam Situational

\section{Communication Crisis Theory (Coombs} \& Holladay, 2010) akan dilihat bagaimana pengaruh krisis pada reputasi organisasi dan behavior intentions dari publik. Dampak yang ditimbulkan memang tidak ada hasil riset pastinya, tetapi menurut Inayah setelah kegiatan manajemen krisis dilakukan masyarakat jadi lebih ter info lagi. Contohnya seperti anak-anak sebagai pelaku yang akan menerima program imunisasi Measles Rubella (MR), mereka menjadi tahu.

Selain itu menurut Anjari, public relations Kementerian Kesehatan tidak memiliki data untuk membandingkan reputasi sebelum dan sesudah penanganan krisis terjadi, tetapi menurutnya andaikan tidak ada penanganan tersebut, maka proporsi seseorang semakin tidak paham akan semakin banyak. Hasil analisis menunjukkan setelah penanganan yang dilakukan, public relations Kementerian Kesehatan tidak melakukan riset mengenai pengaruhnya pada reputasi organisasi, tetapi setelah kegiatan manajemen krisis dilakukan masyarakat menjadi lebih memahami situasi yang terjadi dan akhirnya dapat menerima imunisasi demi menjaga kesehatan keluarga. Meskipun tidak seluruh publik yang dituju melakukan tindakan perubahan, karena masih tetap ada kelompok anti vaksin yang kukuh dengan pendiriannya sendiri. Dalam rilis Kementerian Kesehatan menunjukkan hasil akhir program imunisasi Measles Rubella (MR) di tahun 2017 tercapai yaitu sebanyak 97,69\% atau 34.964.384 anak terimunisasi.

Tahap terakhir manajemen krisis yaitu post-crisis, (Coombs \& Holladay, 2010) menjelaskan tahapan ini sebagai pembelajaran yang diterima organisasi setelah terjadi krisis. Serta tindakan komunikasi apa yang dilakukan oleh organisasi setelah krisis terjadi. Menurut Inayah Kementerian Kesehatan harus lebih masif memberikan informasi dan lebih kuat untuk menggandeng LSM, tokoh agama, tokoh masyarakat kemudian juga media juga harus memiliki hubungan yang baik. Selain itu Anjari menambahkan.

“...Pelaksanaan program ini tidak mungkin dilakukan sendiri tetapi memerlukan orang 


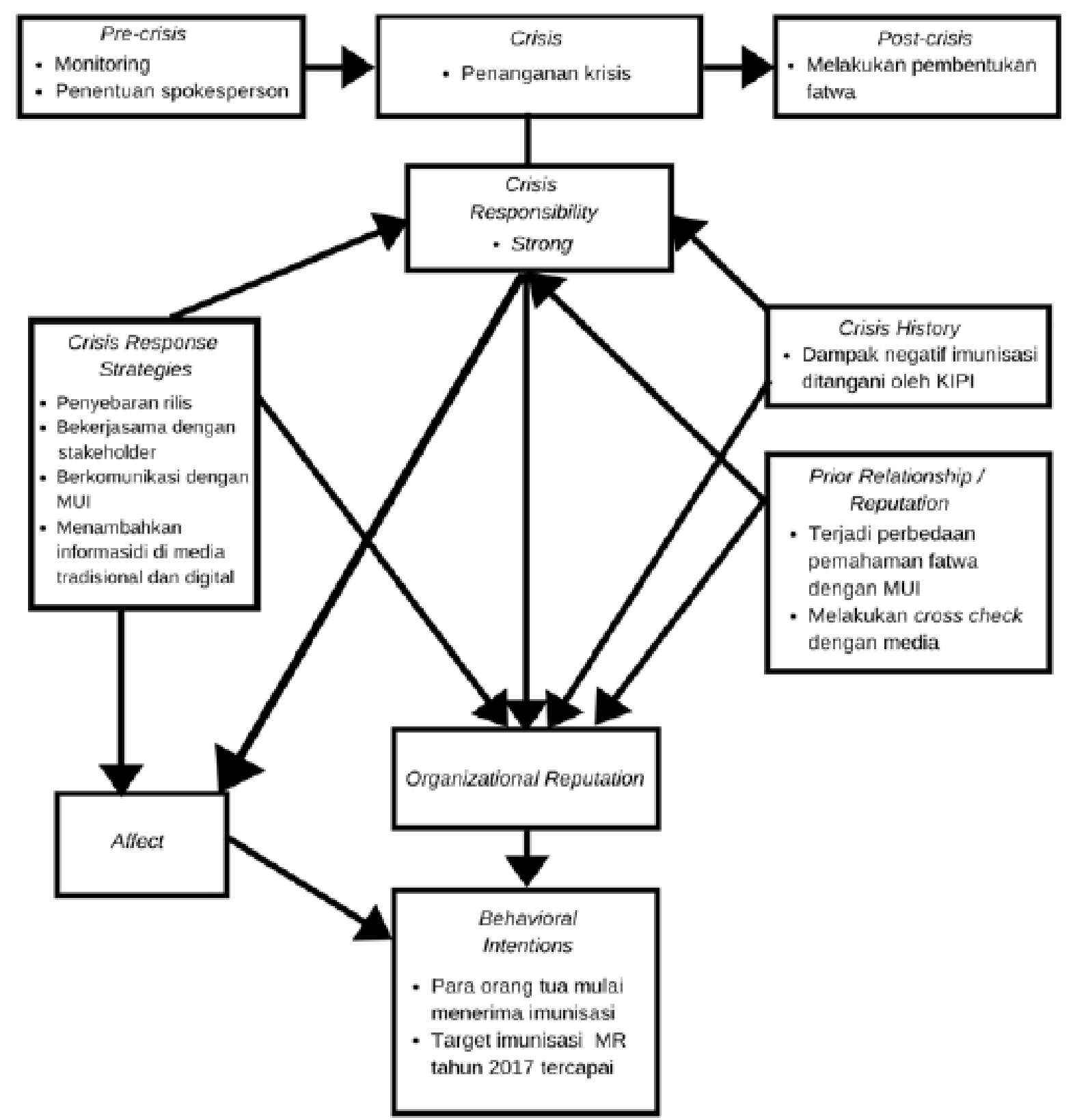

Sumber: Hasil Penelitian, 2019

Gambar 4 Proses Manajemen Krisis dan Model Situational Communications Theory yang dilakukan oleh Public Relations Kementerian Kesehatan

lain. Selain itu adanya pemberitaan miring miring hoaks atau palsu keliru diperlukan strategi khusus untuk menyelesaikannya. Lalu kecerdasan dan literasi masyarakat untuk tidak mudah percaya akan hal-hal seperti itu. Mereka belum mau karena mendapatkan informasi yang memang belum lengkap dapet informasi yang belum utuh dan informasi yang salah keliru atau dapat informasi yang palsu gitu sehingga mereka belum mau..." (Anjari, 26

Desember 2019, komunikasi pribadi).

Hasil analisis menunjukkan banyaknya orang tua yang melakukan penolakan, terjadi karena belum mendapatkan informasi dari 
sumber yang terpercaya. Sehingga membuat mereka mudah untuk percaya akan berita-berita yang tidak jelas kebenarannya. Kementerian Kesehatan dan MUI tetap melakukan dialog untuk membahas dan melakukan penelitian lebih lanjut dalam menetapkan fatwa kehalalan vaksin Measles Rubella (MR).

\section{SIMPULAN}

Berdasarkan hasil penelitian tindakan manajemen krisis yang dilakukan oleh public relations Kementerian Kesehatan pada tahapan pre-krisis, yaitu persiapan krisis seperti monitoring media, penentuan spokesperson, dan pertemuan dengan para stakeholder. Tahapan krisis dianalisis secara mendalam menggunakan seluruh elemen situational crisis communication theory. Crisis responsibility yang dialami, masuk ke dalam kategori intentional dan memberikan ancaman strong. Secara crisis history penolakan program pernah terjadi sebelumnya, dan public relations Kementerian Kesehatan menggunakan strategi yang sama dalam menangani masalah dampak negatif peristiwa imunisasi. Pada elements prior reputation ditemukan kesalahpahaman acuan fatwa yang dilakukan oleh Kementerian Kesehatan.

Hasil analisis penelitian menunjukkan crisis response strategies yang dilakukan yaitu diminish atau pengurangan kejadian krisis.
Sebagai upaya penanganan penolakan dari para orang tua, Public Relations Kementerian Kesehatan bekerja sama dengan Dinas Kesehatan dan Pemerintah Daerah. Mereka ikut serta untuk melakukan pendekatan kepada para orang tua yang melakukan penolakan. Bekerjasama dengan Komnas Kejadian Ikutan Pasca Imunisasi dan menjaga hubungan dengan media melalui media visit dan dilakukan kegiatan cross check informasi. Affect ataupun pengaruh yang ditimbulkan tidak terlihat dari sisi organizational reputations, terjadi perubahan behavioral intentions karena program mencapai target sebanyak 97,69\% atau 34.964.384 anak terimunisasi. Tahap terakhir dalam manajemen krisis, pihak Kementerian Kesehatan melakukan dialog dengan MUI untuk menyelesaikan fatwa kehalalan dari imunisasi Measles Rubella (MR).

Adanya media sosial, sosok public relations dituntut untuk bisa mengatasinya dengan kemampuan perhitungan eskalasi dan juga tindakan respons yang sama cepat. Kecepatan dalam merespons bukan berarti melalaikan kredibilitas dari informasi yang disampaikan kepada publik. Dalam penelitian ini menunjukkan jika organisasi, masih belum cepat melakukan tindakan dan respons dalam menangani krisis. Sebaiknya sosok public relations saat ini, harus mempersiapkan strategi kusus penanganan permasalahan di media sosial agar tidak mudah untuk menjadi krisis. 
Saat krisis melanda (prior reputation) yaitu hubungan yang dimiliki organisasi dengan para stakeholder dapat dimanfaatkan. Peristiwa krisis tidak bisa terselesaikan jika hanya mengandalkan satu organisasi. Dibutuhkan kerja sama dan komunikasi kepada stakeholder untuk membantu dan melakukan penanganan secara bersama-sama. Tindakan komunikasi dan penyelesaian masalah sangat dibutuhkan ketika terjadi perbedaan pemahaman dengan stakeholder.

Pada penelitian ini public relations Kementerian Kesehatan tidak menghitung pengaruh penanganan krisis terhadap reputasi yang dimiliki. Adapun saran bagi kalangan praktisi dan akademis untuk penelitian selanjutnya yang ingin mengangkat topik krisis bisa menggunakan pendekatan yang berbeda seperti kuantitatif. Dengan menggunakan pendekatan yang berbeda, keberagaman penelitian semakin berkembang dan pengaruh dari penanganan krisis yang telah dilakukan bisa terukur dengan jelas.

\section{DAFTAR PUSTAKA}

Akhyar, D. M., \& Pratiwi, A. S. (2019). Media sosial dan komunikasi krisis: pelajaran dari industri telekomunikasi di Indonesia. 11(1), 35-52. https://doi.org/ISSN 26560208

Apuke, O. D., \& Tunca, E. A. (2018).
Social media and crisis management: a review and analysis of existing studies. Sosyal Medya VeKriYönetimi: Mevcut ÇalişmalariIncelemesi VAnalizi., 9(2), 199-215.

Coombs, W. T., \& Holladay, S. J. (2010). The handbook of crisis communication. In Wiley Blackwell. Malden: Blackwell Publishing.

Facebook Kemenkes RI. (2017). Kemenkes tegaskan imunisasi $\mathrm{mr}$ aman digunakan. Retrieved from https://www.facebook. com/KementerianKesehatanRI/

Ham, C. D., Hong, H., \& Cameron, G. T. (2012). Same crisis, different responses: case studies of how multiple competing corporations responded to the same explosion-related crises. International Journal of Business and Social Science, 3(20), 19-31.

ICMI Minta Vaksinasi Rubela Dihentikan. (2017). Retrieved September 8, 2018, from file://Users/wulanyulianti/Documents/ LSPR S2/Journa1/FULL/Daftar Pustaka/ ICMI Minta Vaksinasi Rubela Dihentikan - edunews.id \%7C Merawat Kebhinekaan. webarchive

Jessica, S., \& Ilfandi, A. (2018). Aktivitas public relations angkasa pura ii dalam menangani pemberitaan negatif terminal 3 bandara Soekarno-Hatta the activity of public relations of angkasa pura ii in handling negative news terminal 3 Soekarno-Hatta airport. Jurnal Ilmiah Ilmu Hubungan Masyarakat (Profesi Humas), 2(2), 119135. https://doi.org/ISSN: 2541-3678

Kriyantono, R. (2012). Measuring a company reputation in a crisis situation: An ethnography approach on the situational crisis communication theory. International Journal of Business and Social Science, 3(9), 214-223. 
Kurniawan, D. (2017). Kekecewaan orangtua bocah sd yang meninggal usai divaksin MR - Regional Liputan6. Retrieved from https://www.liputan6.com/regional/ $\mathrm{read} / 3089922 /$ kekecewaan-orangtuabocah-sd-yang-meninggal-usai-divaksin$\mathrm{mr} \% 0 \mathrm{~A}$-sd-yangmeninggal-usai-divaksin$\mathrm{mr} \% 0 \mathrm{~A}$

Lestari, S. (2017). Akibat penolakan dan hoaks, imunisasi massal campak dan rubella MR diperpanjang. Retrieved from BBC Indonesia website: https://www.bbc.com/ indonesia/indonesia-41480450

Mak, A. K. Y., \& AO, S. (2019). Revisiting social-mediated crisis communication model: The Lancôme regenerative crisis after the Hong Kong Umbrella Movement.

Mejri, M., \& De Wolf, D. (2013). Crisis management: lessons learnt from the bp deepwater horizon spill oil. Business Management and Strategy, 4(2), 67. https:// doi.org/10.5296/bms.v4i2.4950

Meyerding, S. G. H., Spiwoks, E., Rombach, M., \& Lehberger, M. (2019). Not only speed matters - Crisis response in the hypothetical case of a transport accident involving genetically modified crops. Food Policy, 85(February 2018), 55-63. https:// doi.org/10.1016/j.foodpol.2019.04.006

MUI. (2018). Fatwa majelis ulama indonesia no. 33 tahun 2018 tentang penggunaan vaksin mr (measles rubella) p. Retrieved March 18, 2019, from https://mui.or.id/wp-content/ uploads/2018/08/Fatwa-MUI-No.-33Tahun-2018-tentang-penggunaan-vaksinMR-measles-rubella-produksi-dari-SIIserum-institue-of-India-untuk-imunisasi. pdf

Olyvia, F. (2017). Menkes jamin vaksin rubella aman dan halal. Retrieved from https://www.cnnindonesia.com/ gayahidup/201708014229-255-232065/ menkes-jamin-vaksin-rubella-aman-danhalal

Prastya, N. M. (2011). Komunikasi krisis di era new media dan social media. Jurnal Komunikasi, 6(1), 1-20. https://doi. org/10.20885/komunikasi.vol6.iss1.art1

Putri, A. W., Sutopo, \& Rahmanto, A. N. (2019). Komunikasi krisis kementerian pertanian pada kasus penggerebekan gudang beras pt ibu (analisis isi kualitatif menggunakan situational crisis communication theory). Jurnal Studi Komunikasi Dan Media, 23(1), 53. https://doi.org/10.31445/ jskm.2019.1765

Sugianto, S., Don, Y., \& Doho, B. (n.d.). (2019). Analisis komunikasi public relations pada sekolah sma don bosco ii untuk mempertahankan citra sekolah katolik yang berkarakter. 4(April 2019), 63-76.

Suryani, I., \& Sagiyanto, A. (2018). Strategi manajemen krisis public relations pt blue bird group. Communication, 9(1), 103. https://doi.org/10.36080/comm.v9i1.624

West, R., \& Turner, L. H. (2010). Introducing communication theory, forth editions. New York: McGraw-Hill.

WHO. (2017). Ajakan aksi. kementrian kesehatan Indonesia. Retrieved from http://www.searo.who.int/indonesia/topics/ immunization/mr_call_for_action.pdf

Yin, R. K. (2014). Case Study research design and methods. London: SAGE Inc. 